\title{
Retikulumzellen und ihre Abkömmlinge in der Nasenschleimhaut des Menschen.
}

\author{
人の學粘膜の細網細胞とその派生細胞.
}

Masaji SEKI 関 正 次.

[Eingegangen am 8. Juni 1952.]

Im subepithelialen Bindegewebe der Nasenschleimhaut bilden bekanntlich die Retikulumzellen den Mutterboden. In den Maschenräumen des Retikulums finden sich beim normalen Zustand nur wenige freie Zellen. Auf langdauernden schwachen pathologischen Reizen vermehren sich aber monocytäre Formen, Histiocyten, grobgranulierte Leukocyten u. a., dabei wird das Retikulum mehr oder weniger stark abgelüst. Von rhinologischer Seite ist jedoch unseres Wissens die letztere Tatsache noch nicht viel geachtet worden. Der Zweck dieser Mitteilung ist anzugeben. welche Befunde wir am menschlichen Material erhalten haben, und speziell wie klar und deutlich dabei eytoplasmatische Zusammenhänge der Retikulumzellen und Ühergänge von den letzteren zu verschiedenen. Zellarten in unseren Präparaten gezeigt wurden. Gewicht wurde auch auf die Untersuchung der Granula der sog. eosinophilen Zellen und der RUSSELLschen Körperchen gelegt.

\section{Material und Methode.}

Das Material, das uns in vorliegender 'Arbeit zur Verfügung stand, stammte von durch Erhängen und an verschiedenen Krankheiten gestorbenen etwa 30 Leichen von verschiedenen Altern, die alle durch eine Injektion von Formalin in die Blutgefäße fixiert und lange in eine Formalinlösung aufbewahrt wurden, und von einer 35 jährigen plötzlich an der Hirnblutung gestorbenen Leiche, deren Fixierung durch eine Injektion der WITTMAACKschen Flüssigkeit (K-Bichromat + Formalin + Essigss̈ure) in die BlutgefäßBe erfolgte. Das den Leichen entnommene Material wurde zumeist, weil es das Knocngewebe enthielten, in einer Salpetersäurelösung entkalkt. Dann Celloidineinbettung. Die Schnitte Jießen sich teils nach der v. MÖLLENDORFFschen Eisenhämateinlackmeth de (1926), teils mit Hämatoxylin und Eosin färben. Die nach der ersten Methode gefärbtın Schnitte wurden anfangs mit Eisenalaun (etwa 3 Min.), später aber mit 10\%iger Essigsüure (etwa 20-60 Min.) differenziert, damit die Schnitte samt dem Celloidin nicht diffus bräunlich angefürbt würden. Andere Für bungen für spezielle Zwecke werden später je nach Erfordernis verwiesen. 


\section{Untersuchung an den Wandungen der Nasenböhle.}

Die Nasenschleimhaut ist im Leben den mit der Inspiationsluft eingeführten verschiedensten reizenden. Stoffen, Virus und Bakterien direkt ausgesetzt, so daß in ihr stets mehr oder weniger starke Veränderungen hervorgerufen werden. Ob eine Veränderung im Präparat nur eine reaktive oder eine krankhafte ist, läßt sich of nicht leicht entscheiden. Des weiteren, selbst die Nasenschleimhaut von. der Leiche, die vor dem Tod über keine Nasenkrankheit klagte, und von derjenigen, die durch Frhängen oder an Hirnblutung plötzlich gestorben war, kann. nicht zur Norm gewanlt werden. Die Nasenschleimhaut ist aber für uns Histologen deswegen von höchstem Interesse, weil sie uns immer vielfältige Zellveränderungen zeigt.

\section{Pars respirateria.}

Ganz allgemein ist das Bindegewebe bestehend ans schönen Retikulumzellen oder aus Fibrocyten mit langen Ausläufern und eingelagert von wenigen freien Zellen als ein nicht oder in geringem Grade verändertes aufzufassen. Die Abb. $1-3$ ist von der subepithelialen Sc'icht, Drüsenschicht bzw. tiefsten Schicht der Schleimhaut der unteren Muschel. Man sieht in ihnen nur vereinzelt freie Zellen. Die Retikulumzellen sind am zierlichsten in der subepithelialen Schicht (Abb. 1). In der sohief ge-

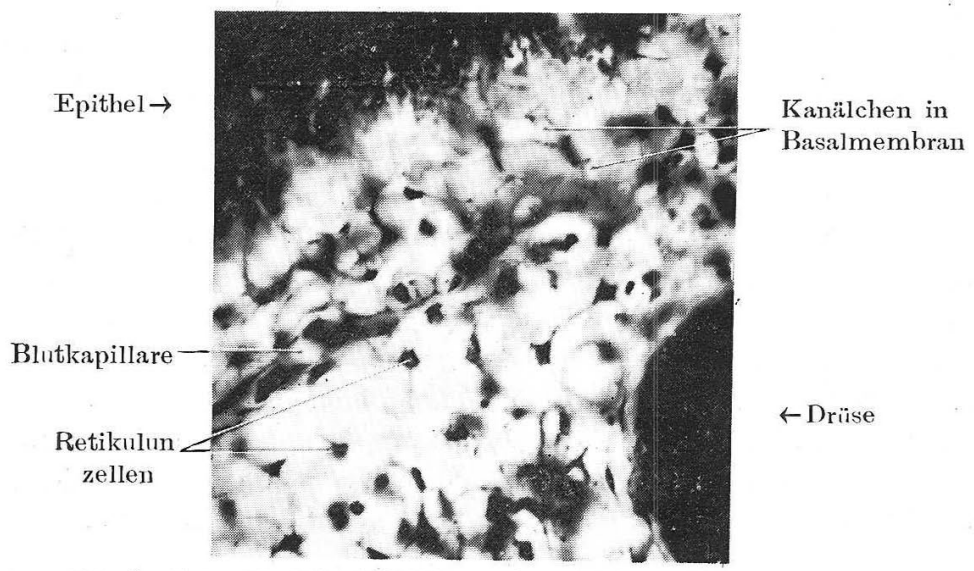

Abb. 1. Subepitheliale Schicht aus dem hinteren 'Teil der unteren Muschel, zur Oberfläche schräg geschmitten (14j. Meningitis tuberculosa, Eisenhämateinlackmethode, $50 \ddot{u} \times)$. Normales Bild.

schnittenen Basalmembran sind Kanälchen deutlich zu sehen, in welchen sich an vielen Stellen Retikulumzellen finden und an die eine Wand des Kanalsystems anschmiegen. In den tieferen Schichten vermehren sich die kollaggenen Fasern zwischen den Zellen, welch letztere die plasmatischen 


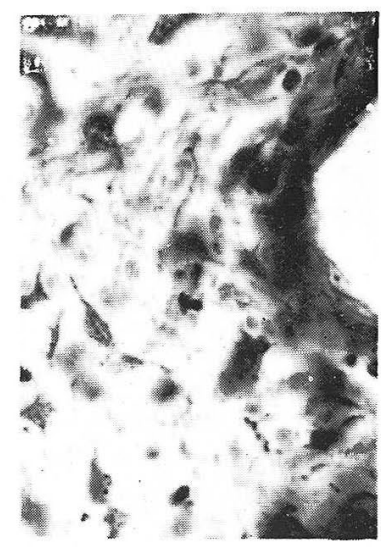

Abb. 2. Flachschnitt durch die Drïsenschicht der unteren Muschel (35j. Hirublutung, Eisenhümateinlackmethode, 500 $x)$. Normales Bild. Auch nur wenige freie Zellen.

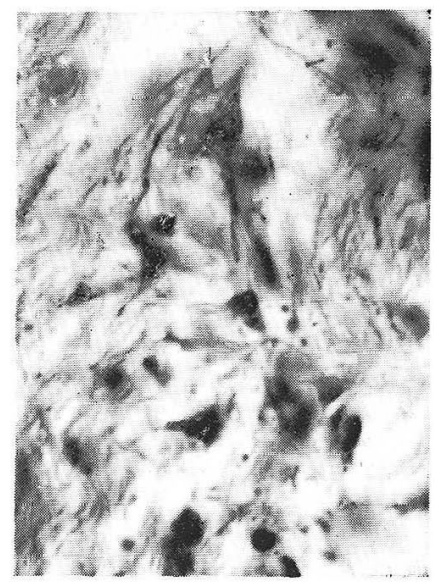

Akb. 3. Flachnitt durch die tiefste Schicht der Schleimhaut der unteren Mushel (35j. Hirnblutung, Eisenhämateinlackmethode, $500 \times$ ). Normales Bild.

Verbindungen zum Teil verlieren ( $\Lambda$ bb. 2 u. 3). Die $\Lambda$ bb. 4 ist auch von der subepithelialen Schicht, in welcher aber Bildung mancher freien Zellen im Gang ist.

Leukocyten können, wie wir es oft bemerken, die oben erwähnten präformierten Kanälchen durch die Basalmembran zur Auswanderung: benutzen. Die Kanälehen müssen aber zugleich gewisse Fremdkörper in der umgekehrten Richtung von außen nach innon durchtreten lassen. $\mathrm{V}$ on besonderem Interesse ist hier die Versuche von YOFFEY und DRINKER (1938). Danach wurde der in die Nase eingeträufelte Farbstoff Trypanblau in kurzer Zeit wieder in der Tymphe des Truncus jugularis nachgewiesen, und zwar beim Kaninchen in 14 Min., bei dem Affen und der Katze in 15-30 Min, und beim Hund in 51-53 Min. Die Retikulumzellen und ihre Abkömmlinge in der subepithelialen Șchicht kommen jedenfalls mit

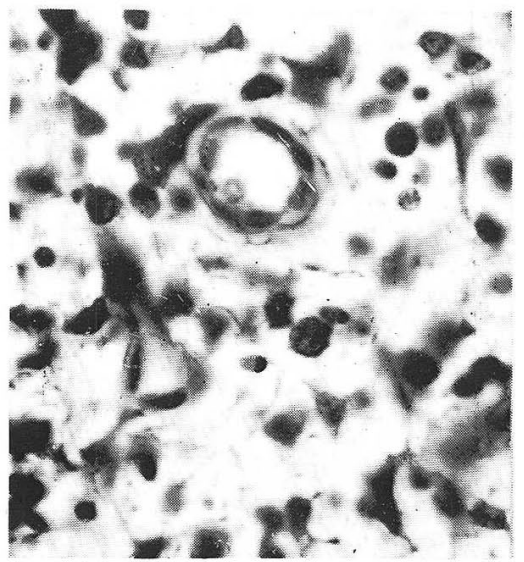

Abb. 4. Flachschnitt durch die subepitheliale Schicht der unteren Muschel (35j. Hirnblutıng, Eisenhämateinlackmethode, 5iji) $\times$ ). Mässige $/ / \mathrm{ell}$ ablösungsvorgänge und Entstehen von freien \%ellen. 


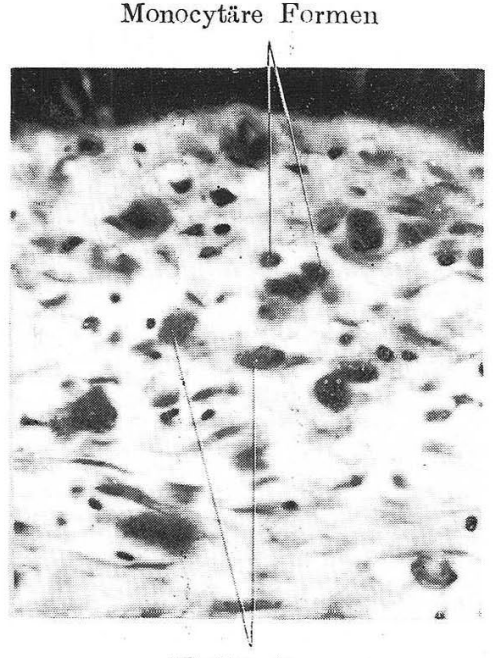

Histiocyten

Abb. 5. Subepitheliale Schicht aus dem hinteren 'Teil der untaren Muschel (14j. Meningitis tuberculosa, Eisen hämateinlackmethode, $50 i i \times)$. Entstehen der Histiocyten und monocytären Formen auf Kosten der Retikulumzellen. Daneben einige I,ymphocyten.

daraus in weitem Maße vertrieben sind (SEKI, 1933). Nach der Formalinfixierung mit oder ohne nachtrügliche Säurebehandluug färben sich die Granula gewöhnlich mit basischen Farbstoffen stärker als mit sauren. Es gibt aber auch solche Histiocyten, deren Granula, besonders gröbere, sich selbst nach der Forma!infixicrung fast nur mit sauren Farbstoffen färben lassen, da in ihnen keine bedeutende Menge von basophilen sauren Substanzen deponiert sind (Abb. 7, Hämatoxylin-Eosinfärbung; s. ferner Abb. 6). Diese Zellen können acido- durch das Epithel eingetretenen giftigen Stoffen, Virus und Bakterien in Berührung. Sie bilden hinter dem Epithel sozusagen die zweite schutzende Front.

Von den Abkömmlingen der Retikulumzelln seien fürs erste die Histiocyten eingehend zu untersuchen.

\section{a) Histiocyten.}

Sie entstehen hauptsächlich aus den Retikulumzellen (in den tieferen Schichten der Schleimhaut aber aus den Fibroeyten) durch Finzichen der Ausläufer und Hypertrophie (Abb. 5 u. 6). Sie werden von Granula verschiedener Größe erfüllt, welche nach einer Fixierung in einem Basenfällungsmittel, wie Bichromat, Pikrinsäure, und besonders nach einer darauffolgenden Säurebehandlung mit Eosin intensiv färbbar sind, da danach die basische Trägersubstanz der Granula sich gut konserviert haben, dagegen die aufgespeicherten basophilen sauren Substanzen

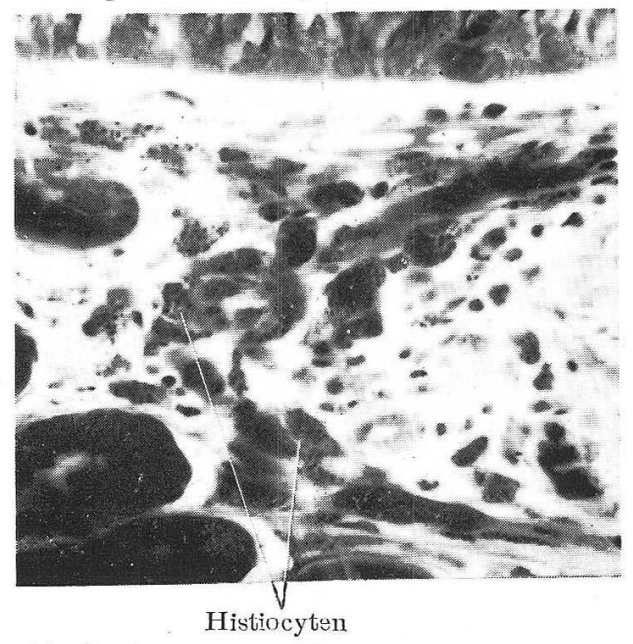

Abb. 6. Subepitheliale Schicht aus dem vorderen Teil der Nasenscheidewand (14j. Meningitis tuberculosa, Eisenhämateinlackmethode, $5001 \times$ ). Massenhafte Histiocyten. Die großeren Granula in den /ellen sind, wie RUSSEILL-Körperchen, mit Eosin intensiv rot fürbbar. 

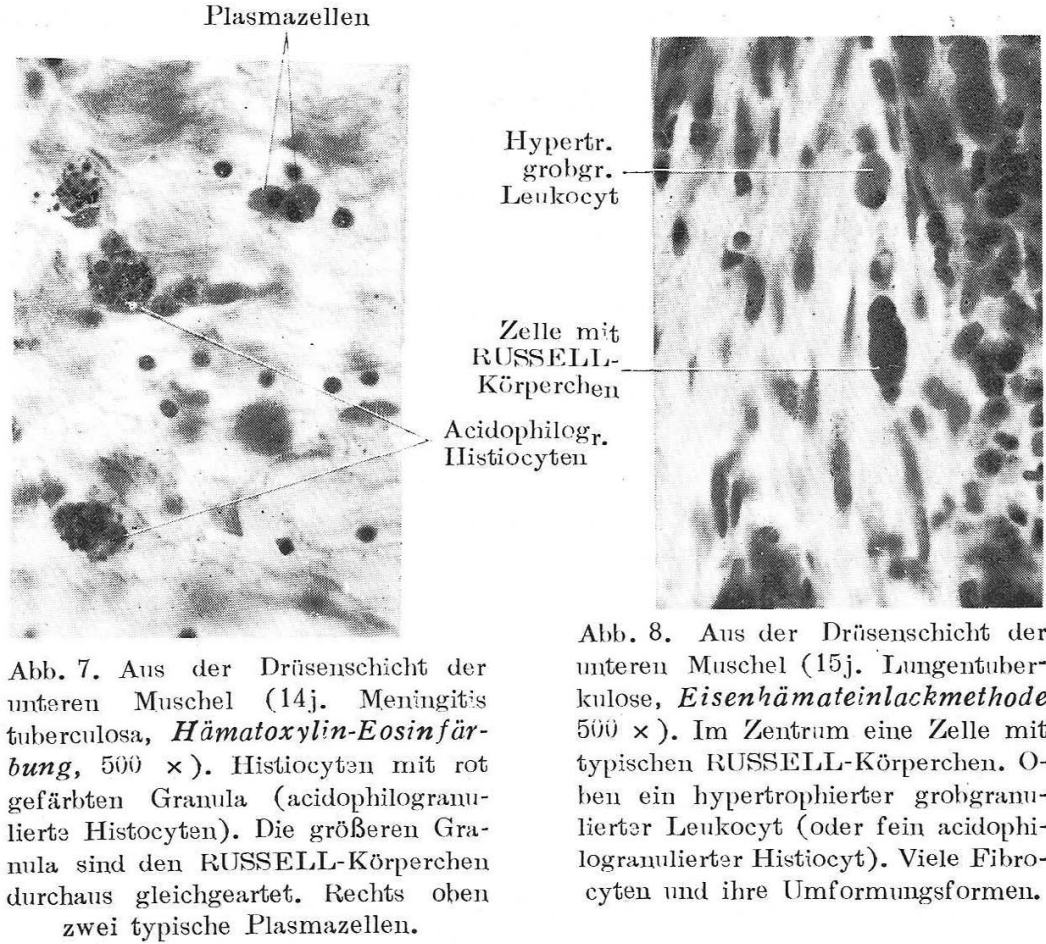

Abb. 8. Aus der Drïsenschicht der unteren Muschel (15j. Lungentuberkulose, Eisenhämateinlackmethode 5iji) $x$ ). Im Zentrim eine Zelle mit typischen RUSSELL-Körperchen. Oben ein hypertrophierter grobgramuliertar Lenkocyt (oder fein acidophilogranulierter Histiocyt). Viele Fibrocyten und ihre Umformungsformen.

philogranulierte Histiocyten hei ßen, die anderen aber basophilogranulierte.

$\mathrm{Zu}$ bemerken ist hierbei, daß der isoelektrische punkt der Granula der Histiocyten mit einer Zunahme der Aufspeicherung von sauren Substanzen natürlich nach der stärker sauren Seitз rückt, so daß der Punkt als kein Maßstab zur Bestimmung der Reichlichkeit von basischen Substanzen genommen werden (SEKI, 1937). Nicht unerwähnt möchtэn wir lassen, daß LISON und FAUTREZ (19.10) unsere Meinung über den Mechanismus der Vitalfärbung mit Säurefarbst fffen ablehnten, sich aber dabei allauviel Kleinigkeiten abgaben und auf die stark bevorzugte Farbstoffdeponierung in den Histiocyten und Retikuloendothelien kein Gewicht legtæn. Sie gingen offenbar fehl, als sie zum einfachen SehlnB kamen, wörtlich: „tous les colorants acids sont athrecytables, à l'exception des phtalcines". Sie nahmen übrigens gar keine Rücksicht auf unsere ergänzenden Arbeiten in 1934 und $1935 \mathrm{~b}$,

Die Entstehung der acidophilogranulierten Histiocyten ist auf zweierlei Weise möglich, entwoder verdauen sich die in den Histiocyten granulär gespeicherten basophilen sauren Substanzen rasch bzw. gehen bald von den Granula aus, hinterlassen aber die basische Trägersubstanz der letzteren, 
oder die Histioeyten speichern Lipoide anstatt der ausgesprochen basophilen sauren Materien auf. Die Frage nech dem Entstehen der Lipoidogranula ist besonders noch aufklärungsbedürftig. Lazu ist vor allem eine Reihe 'Tierexperimente erforderlich. Es würde aber zu weit führen, hier im einzelnen die Resultate unserer diesbezüglichen Experimente zu gehen. Wir mëchten un\$ also in folgenden nur einige kurze Bemerkungeu über die in der Nase sehr häufig a uftretenden sog. RUSSELL-Körperchen gestatten, welche unseres Erachtens durch Reichtum an lipoid- oder wachsartigen Substanzen charakterisiert sind.

Die typischen RUSSELL.Körperchen (Abb. 8, 14 u. 19) sind kugelig, stark lichtbrechend und befinden sich in einer Art Zellen, welche nach unserer Meinung als eine Abart der Histiocyten sowie der grobgranulieiton Leukocyten aufzufassen ist. Die Körperchen färben sich mit Eosin und Säurefuchsin hellrot mit einem wachsartigen Glanz, mit einem einfachen basischen Farbstoff und einem Hämateinlack aber schwächer, sind daher als acidophil zu bezeichnen. Sie sind sicherlich dicht strukturiert, da sie, wie schon FICK (1908) es schrieb, bei der VAN GIESONschen Färbung selbst dann eine gelbe Farbe annehmen, wenn man ein solches Farbgemisch benutzt, in welchem die großmolekulare rote Komponente die kleinmolekulare gelbe dei weitem überwiegt, und da sie fernerhin nach der WEIGER'Tschen Fibrinfärbung blaubiolett zur 1)arstellung gebracht werden können'. Die Körperchen müssen aber zugleich an lipoiden Stoffen reich sein. Denn crstons gehen sie, wie RUSSELL (1890) selbst es bemerkt hat, mit Karbolwasser-Fuchsin eine reichliche und feste Verbindung ein und lassen sich durch Abspülen in Alkohol nicht leicht entfärben (also der Name Fuch. sinkörper) $)^{2}$ zweitens sind sie, worauf MLLLER (1910) hingewiesen hat, doppelbrechend und nach der WEIGER'Tschen Markscheidenfärbung darstellbar. Die RUSSELL-Körperchen sind kurzhin dicht strukturierte lipoidreiche Gebilde. Eine beträchtliche Anreicherung weniger fester Lipoide in den histiocytären Zellen ist übrigens bei der GAUCHERschen und NIEMANNschen Systemerkrankung zu sehen (s. hierzu unter anderem EPS'TEIN, 1924 und BLOOM, 1925).

Die Lipoide sind elekt:ochemisch undedeutend wirkende, dipolschwache Stoffe und also eigentlich weder stark basophil noch stark acidophil. Lipoipreiche Gebilde nehmen allerdings in der Mehrzahl der Fälle, von dem $\mathrm{pH}$ des Mediums weitgehend nnabhängig, saure Farbstoffe besser ein

1 Vgl. hierzu unsere Arbeit über die Darstellung der Neurogliafasern nach WEIGERT in Z. Zellforsch. 29 (1939). S. 553.

${ }^{2}$ Vgl. herzu unsere Arbeit über die Färbung lipoidreicher Gebilde in Z. Zellforsch. 27 (1938), S. 620 und eine andere Arbeit in Okajimas Fol. anat. jap. 19 (1940) $)$, S. 53 . 
als basische, wie z. B. eosinophile Leukocytengranula ${ }^{1}$, pseudoeosinophile Granula des Kaninchens ${ }^{2}$, Dotterkörner und Nervenmark. Die Fäbung der lipoidreichen Gebilde mit sauren Farbstoffen geht nach dem Prinzip der Durchtränkungsfärbung, wobei die VAN DER WAALSschen Kräfte zwischen den Lipoid- und Farbstoffmolekülen eine wichtige Rolle spielen. Daß dagegen basische Farbstoffe gewöhnlieh aus der wässerigen Lösung de lipoidreichen Gebilde nicht stark färben, beruht wahrscheinlich darauf, daß erstens sie an die Oberfläche der letateren dünn niederschlagen (eine schwache Niederschlagsfärbung) und den nachfolgenden Farbstoffteilchen den Weg verstopfen, daß zweitens im Innern der lipoidreichen Gebilde im Gegensatz zu den meisten porösen histologischen Flementæn Räume für Farbst)ffniederschlagen nicht reichlich vorhanden sind.

Nach der allgemein akzeptierten Ancchsuung sollen die RUSSELLLKörperchen bei den versehiedensten pathologisehen Prozessen in den Plasmazellen entstehen. Es ist jedoch in Betrecht zu ziehen, Aaß zur Zeit, als die RUSSELL Körperchen erst Gegenstand lebhafter Untersuchungen wurden,

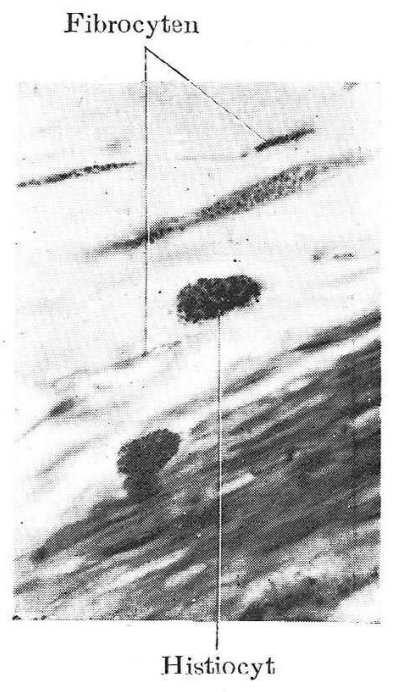

Abb. 9. Flachschnitt durch die tiefste Schicht der Schleimhaut der mittleren Muschel (14j. Meningitis tuberculosi, Eisenhämateinlackmethode, $500 \times$ ). Man sieht Übergänge von Fibrocyten zu Histiocy tan.

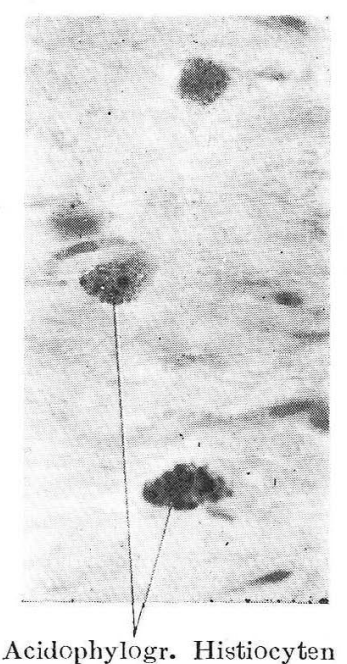

Abb. 10. Flachschnitt durch dieselbe Gewebeschicht wie in Abb.9 (Hämatoxylin-Eosinfärbung). Die größeren Granula in den Histiocyten (sog. RUSSEI,L-Körperchen) sind mit Eosin intensiv gef ̈̈rbt.

1 Nach NEUMANN (1928) ist der Träger ihrer acidophilen Eigenschaft fettartig und frei von Sticktoff, also nicht basisch.

2 Über den Reichtum der Psendceosinophilen Granula an lipoiden Stoffen siehe unsere Arbeit in Z. Zellforsch. 27 (1938). S. 290. 


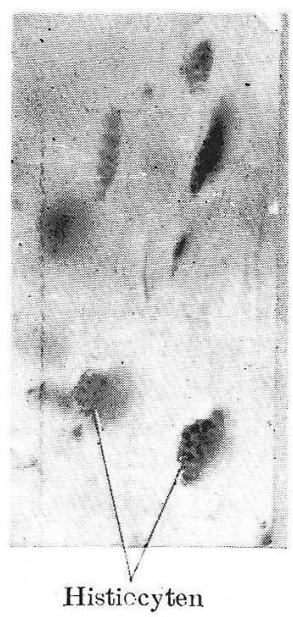

Abb. 11. Flachschnitt durch dieselbe Gewebeschicht wie in Abb. 9 (RUSSELLsche Färbung). Die RUSSELLKörperchen entwickeln sich hier in den aus Fibrocyten entstandenen Histiocyten.

die Forscher über die Histiocyten und monocytären Formen noch keine genaue Kenntnis hatton. Selbst in den verhältnismäßig später erschienenen Arbeitsn von $\%$ B. WEILL und WEIDENREIGH (1920), DUBREUIL Und FAVRE (1921), CHUMA (1923) und KINGSLEY (1924) tangierten nicht diese Zellarten. Ein Durchmustern der Literatur zeigt uns, daß die angeblichen Plasmazellen, in welchen die Entwicklung der typischen RUSSELL-Körperchen im Gang ist, sich von unseren Histiocyten und monocytären Formen mit Acidophilogranula nicht mehr unterscheiden lassen. Den Abb. 9-11 liegen

Präparate augrunde, die mit Eisenhämateinlack, mit Hämatoxylin und Eosin bzw. nach ber RUSSELLschen Methode (Färbung mit Karbolwasser-Fuchsin, Differenzierung mit Alkohol, Differenzierung und Färbung mit KarbolwasserJodgrün) gefärbt worden sind. Die RUSSELL-Körperchen entwickeln sich hier of fensichtlich in ben Histiocyten oder monocytären Formen, derart, daß die anfänglich kleinen Granula sich vergrößern, zum Teil aber zu größeren verschmelzen und zugleich fester und stärker acidophil werden. Der Zelleib bläht sich auf; der Kern wird zumeist an die Peripherie gedrückt und erscheint oft eckig. Endlich werden die Körperchen durch ein Sprengen der Zellmembran im Bindegewede frei gelassen (s. hierzu Abb. 19). Anf die andere Möglichkeit der Bildung der RUSSELLL-Körperchen wird später im Abschnitte der grobgranulierten Leukocyten eingegangen. Zum Schluß sei bemerkt, daß in den histiocytären Zellen der Nasenschleimhaut häufig gelbbraune liehtbrechende Granula eingelagert sind, welche aus Lipofuscin zu bestehen scheinen. Sis sind zu dic'it strukturiert, als daß sie mit einer einfachen wässerigen Farbstofflösung intensiv gefärbt werden könnten.

\section{b) Monocytäre Formen.}

Vorwegs sei erwähnt, daß die Lymphocyten in der Nasenshleimhaut in individuel! und örtlich sehr wcchselnder Menge vorkommen. In nic'at pathologischem Verhältnis ist die Lymphocyteneinlagerung überhaupt keineswegs stark, so daß eine deutliche lymphoide Schicht nicht existiert. In der Nase des Mecrsehweinchens hat DRENNOWA (1929) ein beinahe vollkommenes F'eh'en von lymphoiden Gebilden und eine beträchtliche Zahl der Histiocyten bemerkt. Die lymphoiden Gebilde sind nach seiner Meinung in funktioneller Beziehung, im Sinne ihrer Schutzfunktion, durch die Histiocytzn ersetzt worden.

Das Auftreten einer kleinen Anzahl von monocytären Formen gehört 
zu normalem Befund. Sie entstohen aus Retikulumzellen, Fibrocyten und Lymphocyten (Abb. 5).

Die Plasmazellen wurden anfänglich von Waldeyer wegen ihres Reichtums an Cytoplasma als solche bezeichnet. Aber nacia der Untersuchung von v. MARSCHALKÓ (1895) versteht man unter den Plasmazellen nur den von ihm definierten Typus. Durchblättərt man die einschlägige Literatur, so fällt es uns auf, daß in den meisten Arbeiten, welche sich mit den Plasmazellen befaßten, fast gar keine Rücksicht auf die ihnen weitgehend ähnlichen, in der Funktion aber von ihnen sehr verschiedenen monocytären Formen genommen worden ist In ihnen sind die letzteren Zellemente schlechthin zu den Plasmazellen gerechnet. V. MARSCHALKó (1900) selber hat mit Recht darauf hingewiesen, daß außer den typischen Pasmazellen auch atypische vorhanden sind, die den mononukleären Leukocyten ihren Ursprung verdanken sollen. Nach MAXIMOW (1902) charakterisieren sich die atypischen Plasmazellen des Kaninchens durch eine vie! unregelmäßige Zellform, durch ein schwächer basophiles Cyt’plasma und durch einen viel polymorpheren, größeren, helleren, of tocker netzig gebauten Kern. Er wollte diese atypischen Plasmazellen von den jungen undifferenzierten Polyblasten ableiten. Später zeigte er (1927) eine Art großer Lymhocyten, die auch den Plasmazellen ähnlich aussieht. Markanter Patholog ASCHOFF (1938) beklagte sich aber darüber, daß wie schwer es ist, echte Plasmazellen zu erkennen. Nach unserer Erfahrung ist eine Unterscheidung der echten Plasmazellen von den großen Lymphocyten meist leicht, von den monocytären Formen aber viel schwerer. Zu den obigen, von MAXIMOW angegebenen Artcharakteristika der monocytären Plasmazellen möchten wir noch zwei wichtige hinzufügen.

1. Das Cytoplasma der monocytären Formen ist besonders nach der Fixierung in Basenfällungsmittel oder Methylalkohol (nicht ader in reiner Formalinlösung) von einem ausgesprochen amphoteren (harakter, und in ihm überwiegt zwar Basophilie, aber es zeigt sich zugleich bedeutend acidophil (also mit eosinsaurem Methylenblau rötlichblau färbbar), während das Cytoplasma der Lymphocyten und der rechten Plasmazellen praktisch nur basophil ist (also damit tiefblau färbbar) ${ }^{1}$.

2. Der acidophile basische Bestandteil des Monocytenplasmas scheint sich gegenüber gewissen sausen Stoffen wie ein Fällungsmittel zu verhalten. Im Bindegewebe speichern die meisten monocytären Elemente zahlreiche Granula. Den Lymphocyten und echten Plasmazellen innewohnt aber bekanntlich kein speicherndes Vermögen. Diese zeigen also nach üblichen Färbungen keine ausgesprochene Granulierung des Cytoplasmas (Abb. 7).

c) Grobgranulierte Leukocyten (eosinophile Zellen).

Die Granula der grobgranulierten Leukocyten sind wie erwähnt lipoi-

${ }^{1}$ Siehe SEKI $(1935 a, 1935 b)$. 
dreich. Nach der Untersuchung von WALLGREN (1926) erweisen sie sich in den lebenden Zellen als variable Tropfen und wechseln in Form und Größe. Die grobgranulierten Leukocyten treten am chronisch gereizten Ort der Nasenschleimhaut zahlreich auf. Nur eine geringe Anzahl von ihnen ersheint. wie die grobgranulierten Hämoleukocyten ans, indem sie mit fast gleichmäBig großen eosinophilen Grannla ganz gefülltt werden und einen nierenförmigen oder zweilappigen Kern besitzen. Die Mehrzahl der grobgranulierten Leukocyten in der Nasenschleimhaut ist aber etwas größer, die einzelnen acidophilen Granula sind n:cht gleichgroß und weniger dicht vorhanden, der Kern ist meist rundlich oder kurzoval (Abb. 12). Man kann zwisehen den

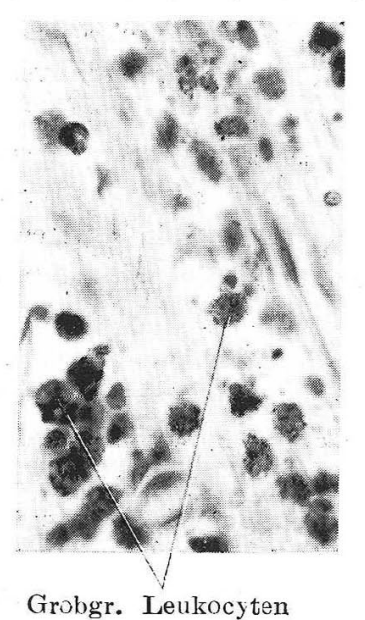

Abb. 12. Aus der Drüsenschicht des mittleren Nasengange (35j. Hirnblutung, Hämatoxylin-Eosinfärbung, $5000 \times$ ). Viele grobgranulierte Leukocyten. Sie sind meist größer als die hämatogenen und haben oft bedeutend große Gramula (Vorstufen der RUSSELL-Körperchen).

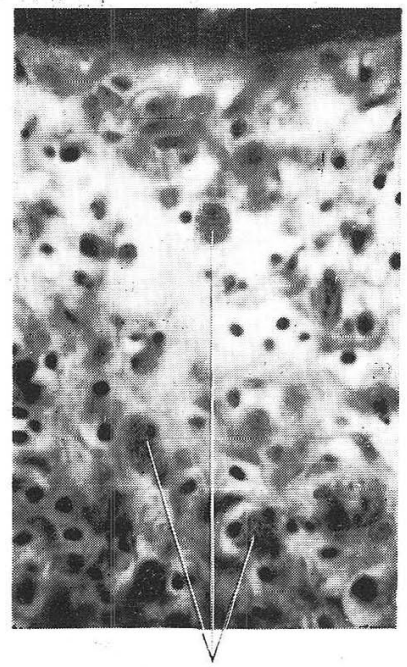

Hypertr. grobgr. Leukccyten

Abb. 13. Subepithelialschicht aus dem hinteren Teil des mittleren Nasengangs (14j. Meningitis tuberdulosa, Hämatoxylin-Eosinfärbung, 5 joi $\times$ ). Drei hypertrophierte grobgranulierte Leukocyten (oder fein acidophilogranulierte Histiocyten), daneben viele Lymphocytäre Zellen.

grobgranulierten Hämo- und Histoleukccyten keine scharfe Grenze zichen.

Die grobgranulierten Leukoeyten in der Nase scheinen, wie es v. MÖLENDORFF (1928) in entzündetem Subkutangewebe bemerkt hat, sich zum größten 'Teil an Ort und Stelle aus den Retikulumzellen oder Fibrocyten oder aber aus den von ihnen entstandenen basophilen Rundzellen zu bilden. In Abb. 12-14 bemerkt man verschiedene Vorstufen der grobgranulierten Leukocyten. Des weiteren, besonders in einer ödematös verquel.lton oder 


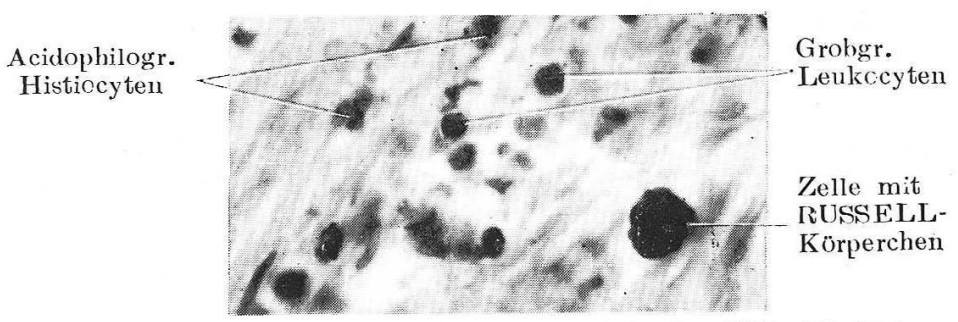

Abb. 14. Subepithelialschicht aus der oberen Muschel (35j. Hirnblutung, Hämatoxylin-Eosinfärbung, 50i $\times$ ). Eine Zelle mit den RUSSELLKürperchen, daneben Histiocyton und Leukocyten mit acidophilen Granula verschiedener Grösse.

hyperplastischen Schleimhaut finden sich oft Zellen, welche als hypertrophierte grobgranulierte Leukccyten oder als fein acidophilogranulierte $\mathrm{Hi}^{-}$stceyten anzusehen sind. Sie sind bedeutend groß und eytoplasmareich, ihr rundlicher Kern rückt zur Peripherie des Zelleibes und nimmt eine exzentrische Lage ein (Abb. 13).

Die grobgranulierten Leukocyten enthalten mitunter nach einer Seite eine klarflüssige Blase. Sie bieten offenbar, worauf v. MÖLLENDORFF (1928) an gleichen Zellen im Subutangewebe hingewiesen hat, den cinen Modus der Auflösung dar. Die Granula der Zellen versehmelzen üdrigens sehr oft miteinander cder lösen sich stark auf, so daß der Zellleib mit der acidophilen Substanz imbibiert wird, eine Erscheinung, die aber zum Teil als eine postmortale Veränderung aufzufassen ist (Abb. 8).

Die als ein charakteristisches Merkmal der allerg:chen Cewebsändcrungen bezeichnete Eosinophilie scheint auch in der Nase hauptsächlich durch cine lokale Fintstehung und Vermehrung der grobgranulierten Leukocyten zustande zu kommen (njeht aber durch eine Versammlung der grobgranulierten Hämoleukocyten). Die größeren Formen der grobgranulierten Leukocyten sind, wie oben erwähnt, in ihrem Charakter den acidophilogranulierten Histocyten gleichgeartet. Z B. B. die von WALSH und LINDSAY (1934) an Nasenpolypen als eosinophile Zellen betrachteten Formen (in Abb. 2, 3 und 4 ihrer Arbeit) sind mit Granula ungteichmäßiger Größo und Färbbarkeit und daneben mit Vakuolen versehen, so daß sie von den grobgranulierten Hämoleukocyten weit abweichen und sich vielmeirr den $H$ :sticeyten nähern.

Dic Granula der grobgranulierten Loukocyten könnon, worauf schon CHUMA (1923) an der Magenschlcimhaut aufmerksam gemacht hat, mit einer weiteren Vergröberung in dic RUSSELL-Körperehen übergehen (s. in Abb. 12 und 14, in welehen versehiedone Zwisehenformen wahrzunchmen sind).

\section{Pars olfactoria.}

In völlig normalem Zustand besteht das subepitheliale Bindegewebe 


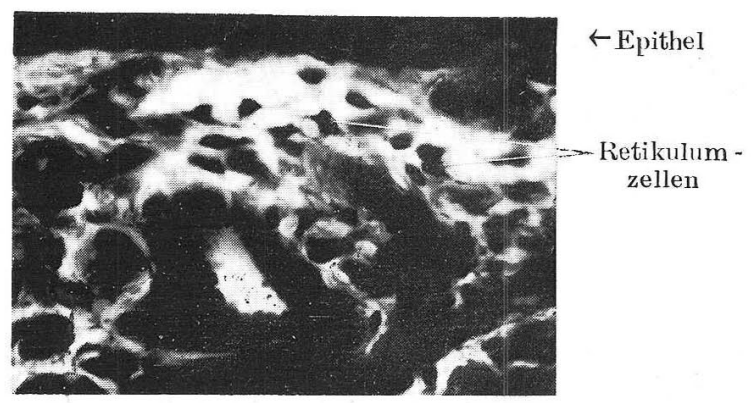

Abb. 15. Aus der Pars olfactoria (15j. Lungentuberkulose. Eisenhämateinlackmethode, 5000 ). Normales Bild.

der Pars olfactoria aus cytoplasmaarmen, mit dünnen Fortsätzen versehenen Retikulumzellen ( $A$ bb. 15). Freie Zellen, wie Histiocyten, monocytäre Eormen, Lymphocyten und grobgranulierte Leukocyten, werden nur ver. ereinzelt angetroffen. Erwähnenswert erscheint, daß KOLMER (1924) manchmal. unter der Basalmembran ausgebreitete, auffallend viele grobe Granula einschließende Zellen fand. Sie traten besonders deutlich an einem mit saurer Fixierungslösung konservierten Material hervor. Diese Zellen sind offenbar aus den Retikulumzellen entstandene Histiocyton. Pathologische Veränderungen sind überhaupt bei weitem seltener und schwächer als in der Pars respiratoria.

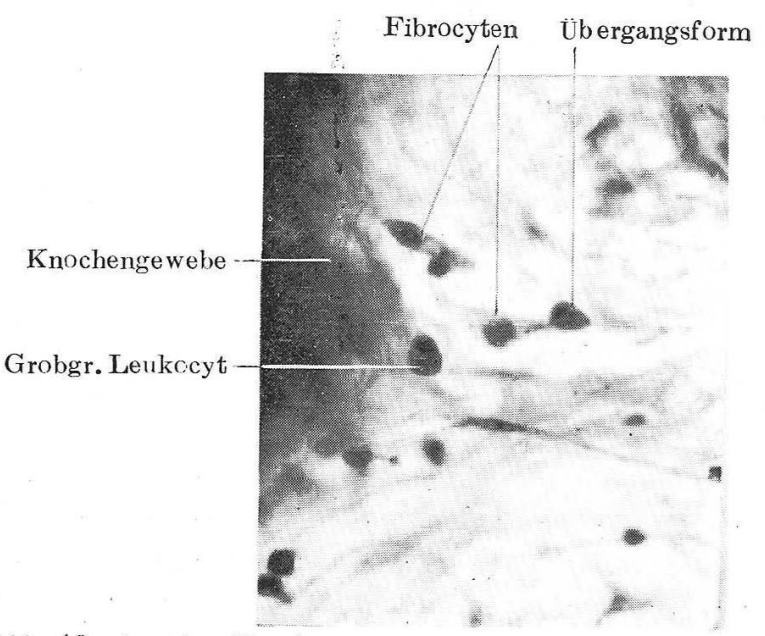

Abb. 16. Aus den Knocheinränmen der unteren Muschel (35j.

Hirnblutıng, Eisenhämateinlackmethode, $5000 \%$ ).

\section{Knochenräume der Muscheln.}

Die Ḱnochenräume der Nasenmuscheln, d. h, die von Knochenbalkchen 
umgesch1ossenen großon Räume (nicht aber die Spongiosaräume) enthalten lockeres Gewebe, das in wesentlichen aus sternförmigen und spindeligen Fibrocyten, Histiocyten, einer Art kugcliger Zellen und Bindegewebsfasern beseht, und Blutgefäße. Die kugeligen Zellen ähneln den grobgranulierten Hämoleukocyten, unterscheiden sich aber, wie es SCHUMACHER (1925) bemerkt hat, von ihnen durch ihre Größe, durch ihren kugeligen, oft exzentrisch gelegenen Kern und durch eine mehr karminrote Färbung der Körnchen mit Eosin. Im übrigen sind die einzelnen Körnchen im Gegensatz zu den Granula in den Hämoleukocyten viclfach nicht gleich groß und nicht gleichmäßig im Zclleib vorhanden (Abb. 16-17). Über die Genese der Zellen gab SCHUMACHFR keinen entsheidenden Aufsehluß. Diese Zellen

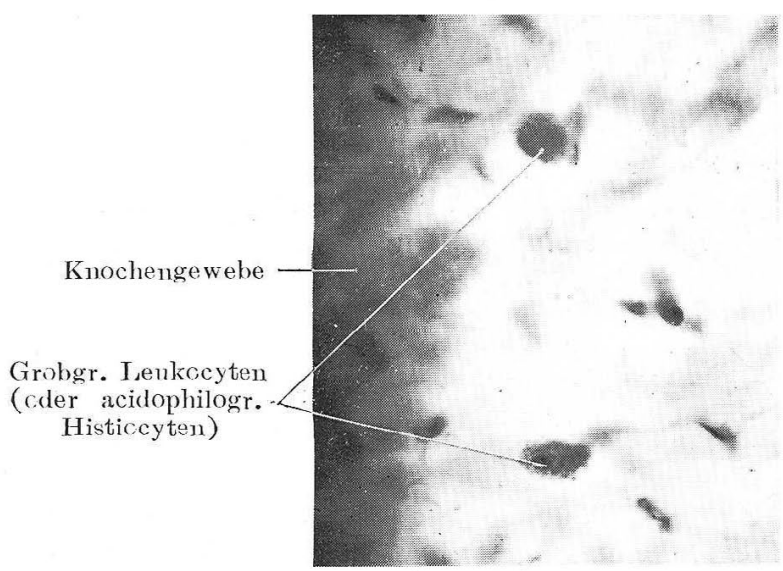

Abb. 17. Aus den Knochenräumen der unteren Muschel (14j. Meningitis tuberculosa, Hämatoxylin-Eosinfärbung, 5ói $\times$ ).

sind unseres Frachtens nichts anderes als die oben bei der Nasenschleimhaut erwähnten grobgranulierten. Leukocyten cder acidophilogranulierten Histiocyten. In Abb. 16 sieht man Übergangsformen zwischen Fibrocyten und den nämlichen. Die Granula können beträchtlich an Große zunehmen (Abb. 17).

\section{Untersuchung an den Wandungen der Nasennebenhöhlen.}

Die Grundlage des völlig normalen subepithelialen Bindegewebes bilden auch hier typische Retikulumzellen ( $\Lambda \mathrm{bb}$. 18). Die Histiocyten, monocytären Formen und Lymphocyten liegen ganz vereinzelt im Bindegewebe. In ödematös gelockertem subepithelialen Gewebe vermehren sich diese Zellen beträchtlich, dazu kommen noch viele grobgranulierte Leukocyten. Das Retikulum wird dabei stark abgelöst.

Die echten Plasmazellen werden selten gefunden. Die von SCHAFFFER 


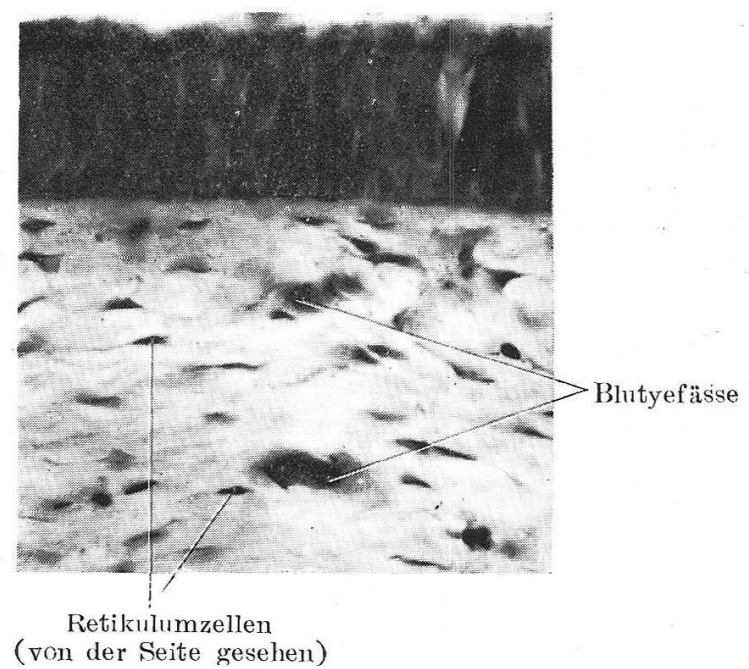

Abh. 18. Subepithelialschicht der Kieferhöhle (17.j. Lungentukerculose, Eisenhämateinlackmethode, $500 \times)$. Normsles Bild. Vgl. hierzı Abb. 1.

(1928) in Abb. 19 seiner Ahhandlung als Plasmazellen dezeichneten Zellen

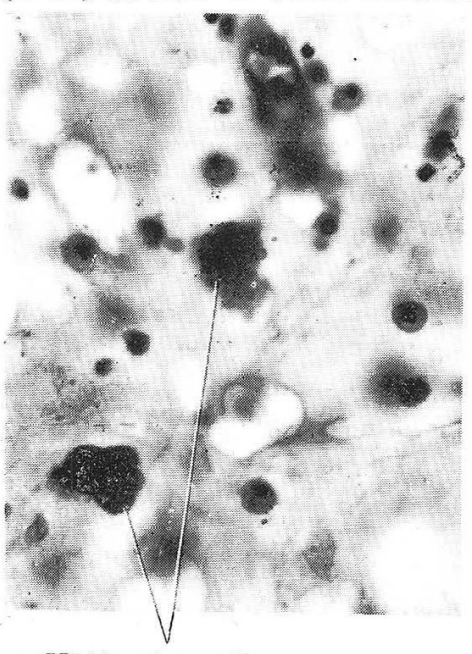

Histiocyten mit RUSSELL-Kröperchen mit körniger wabiger Struktur sind von histio- oder monozytärer Natur.

Die acidophilen Granula der Histiocyten und grobgranulierten Leukocyton können sich stark vergrößern, um zu den sog. RUSSFALL Körperehen zu werden ( $A$ bb. 19).

Abb. 19. Ans der tieferen Schicht der Kieferhöhle (26j. Erhängen, Hämatoxylin-Eosinfärbung, 5iö $x$ ). Zwwei Histiocyten mit großen acidophilogranula (RUSSELL-Körperchen). Daneben einige monocytäre Zellen, Lymphocyten und grobgranulierte Leukocytən. Die betrïchtlich dicker gewordene Gewebeflüssigkeit oder Grundsubstanz zwischen den Zellen ist rötlich gefärbt.

\section{Zusammenfassung.}

1. Das normale subepitheliale Bindegewebe der Nasen- nud Nasennebeṇhöhlen besteht aus Retikulumzellen, ist aber arm an freien Zẹllen. 
Die Retikulumzellen bilden ein Schützwerk gegen verschiedene durch das Epithel eintretende giftige Stoffe, Virus und Bakterien. Der wesentliche Teil der Histiocyten, monocytären Formen und grobgranulierten Leukocyten (eosinophilen Zellen) in der gereizten Nasenschleimhaut scheint lokal aus den Retikulumzellen und Fibrocyten zu entstehen. Lymphocyten werden zwar viel nachgewiesen, aber eine deutliche lymphoide Schicht kommt nicht vor.

2. Die Granula der Histiocyten (und Retikuloendothelien) sind an acidophilen basischen Substanzen reich, Substanzen, die zumeist erst nach dem Wegschaffen der daran deponiert gewesenen sauren Substanzen durch eine Fixierung der Zellen in einem Basenfällungsmittel und besonders nach einer darauffolgenden Säurebehandlung sehr gut erkennbar werden. In chronisch gereizten Geweben kommen aber Histiocyten mit den Granula vor, welche ohne solche Behandlung schon mehr oder weniger stark acidophil sind. Hier handelt es sich entweder um eine intravitale Loslösung der deponierten sauren Substanzen aus der basischen Trägersubstanz der Granula oder aber um eine Aufspeicherung von Lipoiden anstatt der sauren Substanzen. Diese Zellen mit acidophilen Granula nennt man acidophilogranulierte Histiocyten.

3. Ein großer Teil der von den Autoren als Plasmazellen bezeichneten Flemente gehört zu den monocytären Formen. Eincs der wichtigsten Merkmale der monocytären Formen ist der ausgesprochen amphotere (baso- und acidophile) Charakter ihres Cytoplasmas nach einer Fixierung in Basenfällungsmittel. Sie besitzen zugleich die Fähigkeit zur granulären Aufspeichernng von sauren Substanzen. Fs fehlt aber den echten Plasmazellen bekanntlich diese Figenschaften.

4. Die Granula der grobgranulierten Leukocyten sind lipoidreich. Die Mehrzahl der im Bindegewebe der Nasenschleimhaut auftretenden grobgranulierten Leukocyten weicht bezüglich der Größe des Zelleibes und der Beschaffenheit der eingeschlossenen Granula und des Kerns von den grobgranulierten Hämoleukocyten ab. Sie können sich bedeutend vergrößern. Die fein acidophilogranulierten Histiocyten und die hypertrophierten grobgranulierten Leukocyten sind nicht mehr scharf zu trennen.

5. Die RUSSELL-Körperchen entwickeln sich nach allgemeiner Annahme in den Plasmazellen. In der Nase entstehen sie aber in den acidophilogranulierten Histiocyten sowie den grobgranulierten Leukocyten durch Verschmelzung, Vergrößerung und Festerwerden der Granula.

\section{內 容自 抄.}

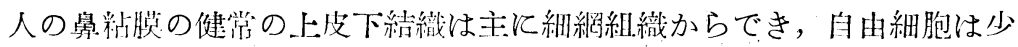
い。毒物やビールスや細菌で则钱せられた糊膜に現れる組織球，单核球， 粗大粒子球（エオンン好性細胞）の大部分はそこの細絧細胞と線維細胞か 
ら生じたもののやうである、リンパ球は多く数へられるが，リンパ様組織 を作るまでには至らない。

組織战の粒子は塩基好性物質を蓄積してるるのが普通で，人はこの蓄積 物質にばかり注意するが，よく検すれば，その物質には同時に酸好性物質 （即ち熄基性物質）が共存する。これは組織を塩基沈降凧で固定し，殊飞続 いて酸で処理すればよく分る。慢性に剌㦸せられた鼻粗膜を搜せば，死後 処理を加へずとも，かやうな多少强く酸好性の粒子を持つ組織球が見觉る。 これには 2 種あつて，その 1 は一旦蓄積した酸性物質を生特に䀣に消化し たり放州したりしたもので，また他の 1 は酸性物質でなく類脂質を攝取し てみるものである。この組織球は好酸粒子組織球と命名せられた。

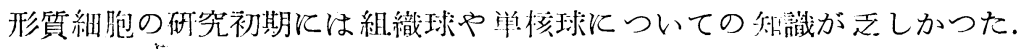
そこで形質細胞と五はれたものには今日の望修球が多く含まれている。单 核球の重要の特徴はその胞形質が塩基沈降㨈で固是せられると渚しい酸好 性を示すことである。酸好性の塩基性物質があればこそ，生持とこの細胞 は酸性物質を粒子として蓄積し得る。風知の如く形質細胞にはその能力が ない。

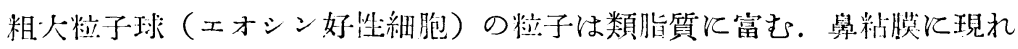
る粗大粒子球の胞体の大さ，粒子と愹の性状等は血液の好酸球のものと違 ふ。この細胞は著しく兆大し得る。さうなれば好酸粒子縕織球と区別でき ない.

Russcll 上粒子は一般には形質細胞肑に生ずると王はれるが，學粘膜で は好酸粒子組織球と粗大白血球に粒子が融合し, 堌大し, 密檏となつてで き得る。

\section{Liter atur.}

Aschoff, L.: Die Monocytenfrage vom anatomischen Standpunkt, besonders ihre Bezielung zum R.E.S. Med. Welt 12 (1938). - Bloom, W.: Splenomegaly ('Type Gascher) and Lipoid-Histiocytosis (Type Niemann). Amer. J. Path. 1 (1925). - Chuma, M: Zur normalen und pathologischen Histoiogie der Magenschleimlart. Virchows Arch. 247 (1923). - Drennowa, K. A.: Das retikuloendotheiiale System der oberen Iuftwege beim Meerschweinchen. W. Hals- nsw. Heilk. 23 (1929). - Dubrenil, G. et M. Favre: Cellules plasmatiques. Plasmazellen à granulations spécifiques. Cellules à corps de Rusell. Archives Anat. microsc. 17 (1921). - Epstein, E.: Beitrag zur Chemie der Gaucherschen Krankheit. Biochem. Z. 145 (1924). - F ick, J.: Beitrag zur Kenntuis der Russellschen Körperchen. Virchows Arch. 193 (19ij8). - Kingsley, D. W. : Regressive structures and the lymphocyte. 'The plasma cell; iț origin and development. Anat. 
Rec. 29 (1924). - Kolmer, W.: Über die Regio olfactoria des Menschen. Mschr. Ohrenheilk. 58 (1924). - Lison, L. et J. Fautrez: L'étude physicochemique des colorants dans ses applications biologiques. Etude critique. Protoplasma (Berl.) 33 (1940)). - Marschalkó, Th. v.: Über die sog. Plasmazellen, ein Beitrag zur Kenntnis der Herkunft der entzündlichen Infiltration. Arch. f. Dermat. 30 (1895). - Die Plasmazellen im Rhinoskleromgewebe. Ein Beitrag zur Kenntnis der sog. Russellschen Körperchen. Arch. f. Dermat. 54 (1900). - Maximow, A.: Experimentelle Untersuchungen über die entzündliche Neubildung von Bindegewebe. Beiter. path. Anat.. Suppl. 5(1902). - Bindegewebe und blutbildende Gewehe. In v. Müllendorffs Handbuch der mikroskopichen Anatomie, Bd. 2, Teil 1. Berlin 1927. - Miller, J. W.: Russellsche Körperchen. Ein Beitrag zu ihrer Entstehung und ihrem Vorkommen bei pathologischen Zuständen des weiblichen Genitraltraktus. Virchows Arch. 199 (1910). - Möllendorff, W. v.: Bindegewebsstıdien. V. Die Ableıtıng der entzündlichen Gewebshilder aıs einer den Bindegeweden gemeinsamen Zellbildungsfolge. Z. Zellforsch.6 (1928).

- Möllendorff, W. и. M. v.: Das Fibrocytemetz im lockeren Bindegewebe; seine Wandlungsfähigkeit und Anteilnahme am Stoffwechsel. Z. Zellforsch. 3 (1926). - Neumann, A.: Über den gegenwärtigen Stand unserer Keminisse üher die chemische Beshaffenheit der Leukocytongranila. Fol. haemat. (Ipz.) 36 (1928). - Russell, W.: An address on a characteristic organism of cancer. Brit. med. J. 1890, 2. - Schaeffer, J.P.: 'The mucous membrane of the nasal cavity and the paranasal sin'uses. Cowdrys Special Cytology, Vol. 1. New York 1928. - Schumacher, S.: Histologie der Lutwege und der Mundhöhle. In Denkers und Kahlers Handbuch der Hals-Nasen-Ohren-heilkunde. Bd. 1, Teil 1. Berlin und München 1925. - Seki, M.: Zur Kenutnis der intra- und supravitalen Färbung. II. Farbanalytische Studien über die Grimdsubstanz der gespeicherten Säurefarbstoffgranula. Z. Zellforsch. 19 (1933). - Zur Kemntnis der intra- und supravitalen Färbing. V. Verdrängende Wirkung nachträglich eingeführten Farbstoffes auf den bereits in Zellen deponiert gewesenen elektisch geladenen Farbstoff. \%. Zellforch. 21 (1934). - Zur Kemtnis der intra- und supravitalen Färbung. VII. Färbbarkeit der Blutmonocyten und ihre elektrische Ladıng. \%. Zellforsch. 22 (1935a). — Zur Kenntnis der intr- und supravitalen Färbung. IX. Färbbarkeit der Plamagrundsubstanz der fixierten Histiocyten, Retikuloendothclien und der weißen Blutzellen von Vögeln, Reptilien und Amphibien. Z. Zellforsch. 23 (1935b). - Contribution à l'étude des colorations intra et supra-vitales. X. Bull. Histol. appl. 14 (1937). - Wallgren, A.: Der eosinophile Iceukocyt in Dunkelfeldbeleucht ing. Arb. path. Inst. Helsingf rors (Jena) 4 (1926). - Walsh, T. E. and J. R. Linsay: Gytology of nasal polypi. Arch. of Ctclaryng. 20 (1934). - Weill, P. u. F. Weidenreich: Über die leukocytären Elemente der Darmschleimhaut der Säugetiere. Arch. mikrosk. Anat. 93 (1920). - Yoffey, J. M. and C. K. Drinker: The lymphatic pathway from the nose and pharynx. J. of exper. Med. 68 (1938). 